\title{
Input saving possibilities and practices contributing to more efficient beef production in Sweden
}

\author{
Gordana Manevska-Tasevska ${ }^{1}$, Helena Hansson ${ }^{1}$ and Ewa Rabinowicz ${ }^{2}$ \\ ${ }^{1}$ Department of Economics, Swedish University of Agricultural Sciences, Box 7013, 75007 Uppsala, Sweden \\ ${ }^{2}$ Department of Economics, Swedish University of Agricultural Sciences, Box 730, 22007 Lund, Sweden \\ e-mail: gordana.tasevska@slu.se
}

\begin{abstract}
This study estimated the possibilities of reducing costs and improving input use in a sample of Swedish farms specialising in beef production. Input use efficiency was measured in a multi-output, multi-input distance function analysis, covering the period 2008-2011. For comparison, both the classical radial and the generalised non-parametric approach were used. The results revealed that on average, costs could be decreased by $20 \%$. Both models constructed frontiers where: i) the rankings of farms according to efficiency were positively and highly correlated and ii) the size and the significance of the parameter estimates were similar. Input-saving technologies were found to be positively influenced by livestock density, pasture availability and the use of coupled income support. Larger farms, farms with higher specialisation in beef cattle, farms with a larger number of animals older than 2 years, farms converting to organic production, farms located in less favoured areas and farms located in regions with a shorter grazing period were found be less efficient.
\end{abstract}

Key words: beef farms, distance functions, efficiency, farm accounting data network, Sweden

\section{Introduction}

The beef sector in Sweden is facing challenges to its development. Compared with other agricultural specializations, Swedish beef production is more variable in terms of the economic benefit (considered in terms of economic output efficiency, where low efficiency implies higher variations in the economic benefit) obtained by farmers (Manevska-Tasevska et al. 2013). This implies that there is great potential for improvement if less successful farms can manage to learn and adopt technologies from the best performing farms. The identification of economically sustainable systems (Salevid and Kumm 2011) and technological improvements (Manevska-Tasevska et al. 2013, Salevid and Kumm 2011) is reported to be crucial for further development of the sector.

Pork and beef are the most often consumed types of meat in Sweden. The demand for beef in Sweden has been continually increasing in recent decades. Compared with the 1990s, beef consumption per person has increased by $70 \%$, with an average increase of around 5\% per annum in the last five years (SCB 2013). In the same period, Swedish beef production has tended to decrease, by on average 1\% per annum (SCB 2013). An important reason is the low profitability in the beef sector. The average gross margin for Swedish beef producers is among the lowest in the EU, both with and without considering the coupled payments (European Commission 2013). Compared with countries with more intensive livestock systems, Swedish beef production can be argued to have advantages, such as lower impact on the environment and production standards adjusted to relatively strong animal welfare legislation (Kumm and Larsson 2007). However, meeting these environmental and welfare requirements makes beef production more expensive, leading to a comparative disadvantage in economic terms. Scientific studies have indicated that after decoupling of the EU income support for beef cattle, the profitability and the interest among Swedish farmers in producing beef may fall even further (Kumm 2005, 2009, Salevid and Kumm 2011). According to Brady et al. (2009), a reduction in commodity output is expected in the livestock sector in general. The decrease in grazing livestock may cause market, social and environmental changes, resulting in lower employment in the sector and difficulties for preservation of biodiversity in Sweden, aspects which could both be positive sideeffects of beef production in Sweden.

Efficiency analysis (Coelli et al. 2005) is a common measurement for defining the cost-saving possibilities and factors contributing to more efficient production. The benefits of more efficient production are expected to be reflected in increased profit margins, more stable production, and even lower environmental footprint from cattle production due to more efficient use of production inputs and the sustainable development of the rural regions in which beef is produced. Efficiency analysis evaluates the amount by which production inputs can be reduced while the level of production is kept constant. Thus it builds on the hypothesis that there are at least some farms in the sample studied that overuse their inputs, but that they can become more efficient by adopting the management strategies 
used by the most efficient farms in the sample. However, efficiency analysis has been criticized for not reflecting the benefits farmers may experience from overusing their production inputs (Asmild et al. 2013, Bogetoft and Hougaard 2003) and may therefore not be suitable for understanding farmers' choices. However, from a policy point of view, efficiency studies provide a good basis for analysis and are important for understanding the factors which promote more efficient farm production and would therefore be the most successful targets for policy measures. The premise in the present study was that efficiency analysis of farms specialising in beef production could help understand how beef production can be encouraged from a policy point of view to contribute to increased production, while still meeting societal goals about rural employment, biodiversity and reduced environmental impacts.

Previous studies on the efficiency of Swedish cattle farms have mainly focused on dairy cattle (e.g. Hansson 2007, Hansson 2008, Hansson and Ohlmer 2008), and thus the findings cannot be directly generalized to other agricultural production types. Cost-effectiveness has been emphasized as an important aspect for obtaining higher comparative advantages in Swedish beef production (Kumm and Larsson 2007). In the literature, the efficiency of beef farms is generally rarely explained. For Sweden, evidence has been provided in some recent studies (e.g. Bostad et al. 2011, Manevska-Tasevska et al. 2013). The analysis provided by Bostad et al. (2011) focuses exclusively on annual use of labour (time spent/bull/period) in specialist beef production. Manevska-Tasevska et al. (2013) investigated the ability of farmers to generate higher revenues while keeping the costs fixed and examined the appropriateness of income support and environmental subsidies to compensate for the losses generated by the low agricultural potential resulting from regional and environmentally sensitive production conditions (for the period 1998-2008). In other studies analysing beef production efficiency in Europe, the influence of the Common Agricultural Policy (CAP) on efficiency appears to be the main issue analysed (e.g. Gaspar et al. 2009, Latruffe et al. 2009, O'Neill et al. 2002). The important issue of how on-farm characteristics, which may be supported in agricultural policy, affect farm efficiency has thus been neglected to date.

The present study examined the relative possibilities for cost savings and improvements in the use of production inputs on Swedish farms specializing in beef production. The study also explored whether factors such as farm structure, capital use and geographical location can lead to more efficient use of production inputs and consequently higher production and environmental benefits. The efficiency in the use of production inputs was measured with a multi-output multi-input function, employing the non-parametric distance function analysis in an input orientation. Farmers' behaviour in terms of how they will use their inputs in order to be more efficient cannot be predicted ad hoc, thus for comparison, both the classical radial distance function (CRDF) approach (Shephard 1953) and the generalized directional distance function (GDDF) (Cheng and Qian 2010, Cheng and Zervopoulos 2012) were employed. The study utilized data from the Swedish Farm Accounting Data Network (FADN) (2008-2011).

The contribution of this study is both empirical and methodological. Empirically, the study contributes to applied research examining how beef production can be conducted more efficiently. Input-saving possibilities were approached by considering how farm structure, capital use and regional factor endowments influenced efficiency. To the best of our knowledge, this is the first study to conduct a comparative analysis of an agricultural production enterprise using two different non-parametric models (CRDF and GDDF). Although the models were applied in parallel, implications arising from model prioritizations were not examined as the main objectives of the study were to examine differences in the results and to discuss the benefits of specific model choice (CRDF vs. GGDF) when analysing a particular agricultural production enterprise. The overall aim was to provide findings of practical use for practitioners and as direct input for discussions by policy makers concerned with the sustainability of beef production, and to make suggestions for further development of the beef sector in Sweden.

\section{Literature review: why might beef farms be inefficient?}

\section{Review of related research and hypotheses about factors associated with the efficiency potential of beef farms}

Based on the existing literature, the factors influencing the economics of beef systems may be generally classified as: farm structure, capital use and regionalization. These are further explained below, followed by specification of the hypotheses tested in this study.

\section{Farm structure}

Labour-saving possibilities, farm size, access to feed resources and changing to organic production are among the most often discussed farm structural characteristics contributing to economic success in Swedish beef pro- 
duction systems. Compared with other European countries, Swedish beef producers are the second most labour productive, after Denmark (European Commission 2013). According to Nyman (2009), who found that savings in the labour costs are related to herd size among the Canadian farmers, this is something Swedish beef producers can benefit from. However, Bostad et al. (2011) claim that while further improvements in the labour efficiency of Swedish beef production systems are possible, factors other than unit size should be given higher attention. Literature findings regarding the effect of unit size on the economic results of beef farms vary. Featherstone et al. (1997) have shown that large beef cow herds in the US are more efficient than smaller herds. However, Ramsey et al. (2005) claim that while economies of size exist in US beef herds in that costs per livestock unit decline as herd size increases, the positive impact on production costs may still not improve productivity per se. A negative influence of farm size on economic efficiency is a typical finding for small-scale cattle fattening production systems (Huyen et al. 2010, Krasachat 2007, Sarma and Ahmed 2011), probably due to shortage of feed resources (Huyen et al. 2010). In addition, average costs per livestock unit can be expected to decline as livestock density increases (Alvarez et al. 2008, Jensen and Kristensen 2013), resulting in a positive economic outcome.

Finishing cattle with grain is reported to be at least three times more land-efficient than grass finishing (Avery and Avery 2007, 2008). However, feeding lower levels of concentrate increases the income efficiency of e.g. Irish beef farms (Finneran and Crosson 2013). Overall, grazing is typically considered the most cost-effective way of meeting the nutritional needs of cattle. Long-grazing systems are low-cost systems using minimal quantities of supplemental feed (mechanically harvested, stored, hauled) (McBride and Mathews 2011, Ramsey et al. 2005) and can be expected to bring the highest economic benefits. Availability of a large area of semi-natural pasture and high environmental grants per hectare for such pasture are reported to be preconditions for good profitability of Swedish beef production (Kumm 2009, Salevid and Kumm 2011). This is contradictory to the finding that the cross-compliance requirement to maintain pasture areas saves jobs, meaning increased need of labour and thus higher costs (Nordin and Manevska-Tasevska 2013). Those authors claim that the extra labour use is primarily increased employer's hours rather than new employment and does not influence the production costs. However this assumes that the farmer cannot use his/her time in any other way but is idle if not working with beef production. One may question whether the benefits (lower feed costs) derived from grazing cancel out the extra labour costs, and thus decrease farm costs overall while leaving production unchanged. Archer and Bergh (2000) and Bostad et al. (2011) concluded that providing feed for animals is a major expense for beef production enterprises. For Swedish farms specializing in beef production, the marginal contribution of the production materials (mostly feedstuff) is twice the marginal contribution of the labour use (Manevska-Tasevska et al. 2013). Moreover, the costs deriving from the need for extra labour are associated with environmental benefits, and are compensated for by a subsidy designed to ensure preservation and continuation of open pasture areas (Nordin and Manevska-Tasevska 2013). Given these findings, it might be assumed that longer pasture-based feeding saves costs. In addition, longer grazing is beneficial for example to animal welfare, the environment, biodiversity, rural landscape values.

Diversification management in terms of the mix of agricultural production on the farm (e.g. crop production, beef production, milk production) appears crucial for long-term profit management, where the balance between production mix decisions, costs and revenues is of significance. According to Phillips and Sorensen (1993), input-saving production systems assume integration of agricultural production enterprises, which can make farmers less dependent on a single output and may mitigate some of the pollution and animal welfare problems. Farm diversification is also associated with a lower risk of feed shortages and thus a lower risk of high production costs. According to Martin et al. (2011), diversity of production activities is a potential strategy to cope with the uncontrollable factors prevailing in grassland-based systems and can potentially ensure farm self-sufficiency in terms of feed.

The economic success of Swedish beef producers is also linked to production type, with organic farming reported to be more profitable. However, the profitability of this production tends to originate from the high environmental payments for producing organically (Salevid and Kumm 2012). Similarly, Manevska-Tasevska et al. (2013) have found that farm support compensates for the high costs of organic farming, making farms producing organically more competitive than conventionally managed farms.

\section{Capital use}

The production efficiency of Swedish beef producers can be improved by implementing technological changes (Manevska-Tasevska et al. 2013, Salevid and Kumm 2011). Such changes in technology do not necessarily involve high capital investments. Adaptations e.g. to cheap outdoor wintering of cattle, finishing of young cattle in open feedlots and re-creation of "extensive pasture mosaics" have been suggested as potential input-saving technologies (Kumm 2005, Nyman 2009). Similarly, according to Ramsey et al. (2005) and Finneran and Crosson (2013), capital investment on beef farms is not clearly related to higher economic benefits. In fact, Finneran and Crosson 
(2013) found capital investment to be negatively associated with income efficiency of Irish beef farms. Ramsey et al. (2005) claim that investments in estate, machinery and equipment can even decrease profits, due to the associated costs of taxes, interest on investments, depreciation, costs for repairs etc. However, the decision to own capital is related to wealth accumulation and asset growth and thus is still expected to contribute to farm profitability.

\section{Regional factor endowments}

The concept of economically sustainable production systems depends on the regional conditions and the sensitivity of the environment. Regional differences in farm performance are a common finding (Barnes et al. 2011, European Commission 2011, Galanopoulos et al. 2006, Hadley 2006, Kumbhakar and Lien 2010, McCloud and Kumbhakar 2008, Sipiläinen et al. 2008, Wang et al. 2012). For Swedish farms specialising in beef production, differences in farm economic performance arising from differing regional and agro-environmental potential have been found to be relatively well compensated by the subsidy support provided for the period 1998-2008 (Manevska-Tasevska et al. 2013). Hansson and Ferguson (2011) suggest that stronger interest in development of farming activities can be expected in farms located far away from urban centres, where there is less competition for land, fewer opportunities for alternative employment and less concern about hygiene issues such as farm odours and noise. Similarly, Salevid and Kumm (2011) claim that in the long term, sustainable profitability of Swedish beef farms in environmental support areas is possible, but that continuous EU income support for beef cattle is necessary (Kumm 2009, Salevid 2013, Salevid and Kumm 2011).

To summarize, the economic success and therefore existence of beef production systems is dependent on micro (farm-related) and macro (region-specific) characteristics. According to the literature, a positive influence on input saving possibilities might be expected from: farm structure, use of capital and regional specifics. Our starting hypotheses related to the expected influence of farm structure, capital use and regional specifics on the efficiency of Swedish beef farms are displayed in Table 1.

Table 1. Hypothesis (H) regarding the influence of farm structure (FS), capital use (CU) and regional characteristics (RC) on farm efficiency.

\begin{tabular}{|c|c|}
\hline \multicolumn{2}{|c|}{ Farm structure } \\
\hline H:FS1: & $\begin{array}{l}\text { In Sweden, where the competition for farm land in most areas is low, farm } \\
\text { size improves farm efficiency. }\end{array}$ \\
\hline $\mathrm{H}: \mathrm{FS} 2$ & Higher livestock density improves farm efficiency \\
\hline H:FS3: & Grazing/existence of grassland has a positive influence on farm efficiency \\
\hline
\end{tabular}

\section{References}

(Nyman 2009)

(Featherstone et al. 1997)

(Ramsey et al. 2005)

(Huyen et al. 2010)

(Alvarez et al. 2008)

(Jensen and Kristensen 2013)

(Ramsey et al. 2005)

(McBride and Mathews 2011)

(Kumm 2009)

(Salevid and Kumm 2011)

(Phillips and Sorensen 1993)

(Martin et al. 2011)

(Phillips and Sorensen 1993)

(Salevid and Kumm 2012)

(Manevska-Tasevska et al. 2013)

Capital

$\mathrm{H}: \mathrm{CU}$ :

High capital investment does not lead to efficient beef production

(Ramsey et al. 2005)

(Finneran and Crosson 2013)

Regional characteristics

$\mathrm{H}: \mathrm{RC}$ : $\quad$ The efficiency of beef production systems is restricted by regional factor endowments 


\section{Measuring resource use efficiency in beef production}

\section{Empirical application}

In this study, the efficiency of Swedish beef production technology was described using the multi-output, multiinput, non-parametric input distance function approach. Effects of beef production practices selected to explain the input-saving possibilities were estimated in an additional step, using the Tobit regression model. Use of a single-output production frontier aggregating the agricultural output into one index (very often total value of farm output) has been a standard approach in farm-level efficiency analysis in numerous studies (e.g. Barnes 2008, Hadley 2006, Latruffe et al. 2004). However, agricultural production is an example where multi-output multi-input technology is typical, even on farms specializing in a particular type of production. Distance functions allow multioutput multi-input technologies to be presented individually, so aggregation biases can be avoided.

Efficiency scores were estimated using the Shepard's (1953) classical radial distance function (CRDF) approach and the Cheng and Zervopoulos (2012) generalised directional distance function (GDDF) approach. Distance function analysis can be applied both for output and input orientation. However, due to the expectation that in the short run farmers have better control over inputs rather than outputs, input orientation was applied here. In its simplest form, the CRDF characterizes the production technology looking at the minimal proportional contraction of the input vector, given an output vector (Shephard 1953). Therefore, the input distance function definition suggests the degree to which the inputs used exceed the input requirement for an observed production enterprise, which is identified as a cost, or inefficiency (Greene 2008). Generalization of Shepard's radial form of the input distance functions has been done by Chambers et al. $(1996,1998)$ through the introduction of a directional input distance function (DIDF). The DIDF measures the amount that one can translate an input vector radially from itself to the technology frontier in a reassigned direction, assuming that the translation is allowed towards all of the points on the frontier that dominate the observed decision-making unit (Färe et al. 2008). Cheng and Qian (2010) and Cheng and Zervopoulos (2012) further generalized the form of the distance function defined by Chambers et al. (1998) by applying the assumption that the changes in the proportions of inputs and output are not necessarily equal.

As for the production frontiers, distance functions can be estimated applying the non-parametric data envelopment analysis (DEA) and parametric distance function (PDF) approach. Although the parametric results are more robust (Alene and Zeller 2005), the choice of the parametric approach is not without drawbacks. It has been criticized e.g. as being more complicated in that: i) the selection of production functions may not be appropriate; ii) it often fails to satisfy the concavity and the quasi-concavity properties; and iii) explanatory variables used to explain sources of inefficiency may be correlated with the composite error term, producing biased estimators (Coelli et al. 2005). Comparative analysis conducted to test the results obtained by the competing parametric and nonparametric models has revealed that both techniques construct production frontiers where technical efficiency is positively and significantly correlated (Alene and Zeller 2005, Coelli and Perelman 1999).

The present analysis was performed using the non-parametric linear programming software MaxDEA, version 5.2 (Cheng and Qian 2010). The CRDR and the GDDF models were both set for input orientation under an assumption of variable returns to scale. The directional vector of the GDDF analysis was specified as "a mean of all decisionmaking units (DMUs)". In the case where the directional vector is set as "the values of the evaluated DMU", the directional distance function model is reduced to the classic input-orientated radial model, i.e. $g_{x}=\mathrm{x}_{0}$ and $g_{y}=\mathrm{y}_{0}$ (in eq. 2). In this study only the existence of desirable outputs was considered. Alternatively, if undesirable outputs are included, an extension containing specifications for undesirable outputs is available (Cheng and Zervopoulos 2012). Assuming that non-undesirable outputs were taken into consideration, the efficiency score was calculated using equations 1 and 2 as follows:

$$
\begin{aligned}
& \text { Efficiency score } \theta_{i}=\min \frac{1-\frac{1}{m} \sum_{i=1}^{m} \beta g_{i / x_{i o}}}{1+\frac{1}{s} \sum_{r=1}^{s} \beta g_{r} / y_{r o}} \\
& \text { s.t. } X \lambda+\beta g_{x} \leq x_{o} \\
& Y \lambda-\beta g_{y} \geq Y_{o}
\end{aligned}
$$

where $\theta i$ is the efficiency score of a producer $i, m$ represents the number of inputs; $s$ is the number of outputs; $x_{o}$ and $y_{o}$ are respectively inputs and outputs evaluated by the $\mathrm{DMU}_{0} ; g_{i}$ and $g_{r}$ are user-defined direction vectors 
of inputs and outputs; and the ratios $\beta g i / \mathrm{xi}_{0}$ and $\beta \mathrm{gr} / \mathrm{yr}_{0}$ indicate the proportion of inputs decreasing and output increasing, respectively. Effects of beef production practices selected to explain the input-saving possibilities were estimated using the Tobit regression models (Tobin 1958) (eq. 3). The non-negative efficiency scores obtained with the distance function analysis (eq. 3) were regressed with the factors selected to explain the input-saving technologies . The error term, $u_{i}$, was assumed to have a normal distribution.

$$
\theta_{i}\left(\begin{array}{lll}
\theta_{i}^{*}=\beta z_{i}+u_{i} & \text { if } & \theta_{i}^{*}>0 \\
0 & \text { if } & \theta_{i}^{*} \leq 0
\end{array}\right) ; \quad u \sim N(0, \sigma) ; \quad i=1,2, \ldots N
$$

Although it can be assumed that proportional lowering of the inputs use (radial form) is easily attainable for all farms, changing the inputs combinations (in order to satisfy the DDIF) might be assumed be constrained with the resource availability at some farms. Farmers' decisions to work with the utilization of inputs cannot be predicted ad hoc, thus a comparative analysis where both models are presented in parallel is expected to provide more accurate results both for the: 1) first stage of the analysis, when farms are ranked based on the efficiency achievement and 2) regression analysis when efficiency scores are regressed with the variable expected to explain the sources of efficiency.

In the literature (e.g. Simar and Wilson 2007), the two stage analysis has been criticised to produce biased results: first in respect to producing DEA efficiency scores (existence of serial correlation because efficiency is assessed in relation to the efficiency frontier), and second in producing a heteroscedasticity problem in the regression analysis, where the error terms are explained to be correlated with the independent variables. However, in many studies (e.g Afonso and St. Aubyn 2006, Larsén 2010, Latruffe et al. 2008, Manevska-Tasevska 2013, Manevska-Tasevska and Hansson 2011) covering different applications the common two-stage approach has not been found to produce substantially different results from the bootstrapped approach; especially with respect to the sign of the estimated coefficients and the statistical significance. Therefore we assume that this study fits to the common understanding as well. As the primary interests of the present study were the sign and statistical significance of the explanatory variables, the conventional two-stage approach was adopted.

\section{Data and variables}

This data used in the study were obtained from the Swedish Farm Accounting Data Network (FADN), which contains detailed financial data as well as some supplementary information on an unbalanced rotating panel of about 1000 farms representing the population of about the 30000 largest farms in Sweden. The sample is stratified according to farm size and geographical location. In this study, farms specializing in beef fattening (according to FADN coding ${ }^{1}$ for farm specialization) were the focus. An unbalanced rotating panel of 381 observations for the entire period 2008-2011 was used. FADN is the only standardized survey-based farm-level dataset in Sweden, and is commonly used in studies analysing farm efficiency, factors contributing to more efficient farming and managerial and policy recommendations for further improvements. Although detailed technological information (such as feeding schemes, grazing arrangements, building structure, breed structure, animal handling etc.) is not included, the dataset was expected to provide comprehensive information for analysing the resource use efficiency, and sufficient information for explaining the farm practices and conditions which drive the resource use efficiency. Descriptive statistics on the variables used for estimation of efficiency scores, determinants of efficient beef production and other supporting farm characteristics are displayed in Table 2.

To estimate the resource use efficiency, two output and six input variables were considered. Outputs were represented by the: i) sales value of the beef and veal produced (output 1), and ii) sales value of the remaining farm production (output 2), both expressed in SEK. Input selection was linked to the typical production characteristics of the beef systems, represented by: i) the number of cattle for fattening, expressed in livestock units (LU) ${ }^{2}$; ii) labour use on the farm, expressed in total working hours; iii) total area utilized, expressed in hectares; iv) feed costs, including value of feed produced on the farm and purchased feed, expressed in SEK; v) energy costs, representing the total value of the energy (including electricity and fuel for heating) consumed on the farm, expressed in SEK; and vi) other animal handling costs (specific livestock costs for veterinary fees, medicine, artificial insemination, castration, registration in herd books, maintaining livestock equipment, short-term rent of buildings used to house animals or storage, marketing etc.), expressed in SEK.

\footnotetext{
${ }^{1}$ The FADN codes for specialization in beef fattening are: 4210 and 4220 .

${ }^{2}$ The livestock unit (LU) is a reference unit which facilitates the aggregation of livestock from various species and age. Specific coefficients are established on the basis of the nutritional or feed requirement of each type of animal. Coefficients for bovine animals are as follows: under 1 year old $=0.4 \mathrm{LU}$, between $1-2$ year old $=0.7 \mathrm{LU}$, male 2 years old and over $=1 \mathrm{LU}$, heifers, 2 years old and over $=0.8 \mathrm{LU}$, dairy cows $=1 \mathrm{LU}$, other cows 2 years old and over $=0.8$.
} 
Effects of factors influencing the input saving possibilities in the beef production system were categorized based on the proposed hypothesis (FS, CU and RC endowments, in Table 1). In addition, farm structure was complemented by herd structure elements and access to capital by direct payments per livestock unit. Descriptive statistics on the selected practices and conditions are displayed in Table 2.

The FS characteristics were explained by: 1) The economic size of the farms, based on accounting data, expressed in European Size Units (ESU) ${ }^{3}$; 2) livestock density index (LDI1), showing the number of cattle fattening livestock units per grazing area, and a livestock density index (LDI2) considering the grazing period (see equation 4).

(Livestock density index $x_{\text {grazing period }}=\frac{\mathrm{LU}}{\mathrm{TUA}} * \frac{\text { grazing period }}{12}$ )

LDI2 was thus the product of the ratio between the number of cattle fattening livestock units per total area utilized and the ratio of the grazing period to a full year. The grazing period used in equation 4 was calculated based on the farm location and national directives (Swedish Board of Agriculture 2013) on the minimum grazing period for that location. Given the directive, three grazing regions were determined, with a four-, three- or two-month grazing period, respectively; 3 ) herd structure, explained by the number of beef cattle in a selected age category, such as: i) cattle younger than 1 year, ii) cattle older than 1 and younger than 2 years, and iii) cattle older than 2 years; 4) farm grazing potential, which was proxied by the total grazing area normalized per LU; 5) specialization, as percentage of earnings coming from beef production relative to the total value of the farm output; 6 ) feed production on the farm, proxied by the feed self-sufficiency index, showing the percentage cost of domestically produced feed in the total feed costs; 7) production orientation showing whether a farm was converting to organic or producing organically, represented with dummy variables having a value $1 / 0$, with conventional farm production taken as a base.

Capital use was explained in terms of investments, loans and direct support, all presented in SEK normalized per LU. Regional factor endowments were proxied by the regional farm grazing potential and belonging to a less favoured area (LFA) ${ }^{4}$. For the regional farm grazing potential, three regions were determined (based on the directives for minimum grazing period (Swedish Board of Agriculture 2013)): Grazing region 1 (Blekinge, Skåne and Halland) with a four-month grazing season; grazing region 2 (Stockholm, Uppsala, Södermanland, Östergötland, Jönköping, Kronoberg, Kalmar, Gotland, Västra Götaland, Värmland, Örebro and Västmanland) with a three-month grazing season; and grazing region 3 (Dalarna, Gävleborg, Västernorrland, Jämtland, Västerbotten and Norrbotten), with a two-month grazing season. Dummy variables having a value $0 / 1$ for farms not belonging/belonging to specific grazing region were used, with grazing region 1 taken as a base. A three-grade scale explained the belonging to a LFA, where 1 = farms where the majority of the area utilized is not situated in LFA and 2 and $3=$ farms where the majority of the agricultural area utilized is situated in LFA and mountainous areas, respectively.

The descriptive statistics (Table 2) showed extreme variations in the outputs (sale values of the beef and veal production), indicating the existence of large differences in the production characteristics of different farms. The average contribution of beef and veal production to the total farm sale value was $71 \%$ (see specialization in cattle fattening in Table 2). In terms of cost structure considered in the analysis, the highest share of total farm costs comprised feed costs. On average, 3327 working hours per year were spent on the farm, to keep $67 \mathrm{LU}$ (131 cattle in different fattening categories) and maintain an area of around 128 ha. For comparison, the average area utilized on French beef farms is 97 ha and farms keep on average 115 LU (Figures for the year 2000) (Latruffe et al. 2009).

${ }^{3}$ One European Size Unit (ESU) is a standard gross margin of EUR 1200 , that is used to express the economic size of an agricultural holding or farm.

${ }^{4}$ Less-favoured area (LFA) is a term used to describe an area with natural handicaps (lack of water, climate, short crop season and tendencies of depopulation), or that is mountainous or hilly, as defined by its altitude and slope. 
Table 2. Descriptive statistics: input-output variables, farm practices and conditions as efficiency factors, based on FADN data 2008-2011, $\mathrm{n}=381$.

\begin{tabular}{|c|c|c|}
\hline Variables & Mean & St. Dev. \\
\hline \multicolumn{3}{|l|}{ Outputs } \\
\hline Sale value of beef and veal production, SEK & 934367 & 1838264 \\
\hline Sale value of the remaining farm production, SEK & 286590 & 390408 \\
\hline \multicolumn{3}{|l|}{ Inputs } \\
\hline Cattle for fattening, livestock units & 67 & 98 \\
\hline Labour use, hours & 3327 & 1953 \\
\hline Total area utilised, ha & 128 & 153 \\
\hline Feed costs, SEK & 597885 & 607950 \\
\hline Energy costs, SEK & 38171 & 30272 \\
\hline Other animal costs, SEK & 71085 & 112871 \\
\hline \multicolumn{3}{|l|}{ Determinants of efficiency } \\
\hline \multicolumn{3}{|l|}{ Farm structure } \\
\hline Farm size, accounting data in ESU (no. of cattle) & $6.7(131)$ & $1.1(189)$ \\
\hline Livestock density LDI 1, LU/grazing area (LU ha-1) & $5.1(0.9)$ & $21.3(1.4)$ \\
\hline Livestock density \& grazing period LDI 2 & .24 & .37 \\
\hline Share beef cattle <1 year, \% & 72 & 18 \\
\hline Beef cattle $<1$ year, no. & 90 & 129 \\
\hline Share beef cattle $>1<2$ year, $\%$ & 17 & 14 \\
\hline Beef cattle $>1<2$ year, no. & 29 & 66 \\
\hline Share beef cattle $>2$ year, $\%$ & 6 & 7 \\
\hline Beef cattle >2 year, no. & 6 & 11 \\
\hline Heifers, no. & 5 & 8 \\
\hline Grazing area, ha per LU & $57(1.3)$ & $102(1.79)$ \\
\hline Specialisation in cattle fattening, \% & 71 & .18 \\
\hline Feed self-sufficiency, \% & .75 & .25 \\
\hline Conventional farming, \% & 50 & - \\
\hline Converting to organic, \% & 46 & - \\
\hline Organic farming, \% & 4 & - \\
\hline \multicolumn{3}{|l|}{ Capital use } \\
\hline Farm investments, SEK/LU & 17403 & 31583 \\
\hline Farm loans, SEK/LU & 45025 & 49705 \\
\hline Coupled subsidies, SEK/LU & 935 & 736 \\
\hline \multicolumn{3}{|l|}{ Regional endowments } \\
\hline Grazing region $1, \%$ & 20 & - \\
\hline Grazing region $2, \%$ & 71 & - \\
\hline Grazing region $3, \%$ & 9 & - \\
\hline FADN Region $1^{\mathrm{a}}$, $\%$ & 63 & - \\
\hline FADN Region $2^{\mathrm{b}}, \%$ & 30 & - \\
\hline FADN Region 3c, \% & 7 & - \\
\hline LFA (three-grade scale) & 1.9 & .55 \\
\hline
\end{tabular}


The average herd size of Swedish beef farms according to national statistics is around 70 LU (SCB, 2013), and is thus similar to the sample studied here. The economic size of the farms included in the dataset was approximately $7 \mathrm{ESU}$ (1 ESU = standard gross margin $1200 \mathrm{eu}$ ). Average grazing area per farm was 57 ha, with an animal density of $5.1 \mathrm{LU} \mathrm{ha}^{-1}$ grazing area and $0.9 \mathrm{LU} \mathrm{ha}^{-1}$ total area utilized.

The livestock density index based on the grazing period (LDI2) is complex to interpret, but when used in the regression it was expected to strengthen the findings for the effect obtained by the first livestock density index (LDI1) and to show the effect of the regional potential. Data on herd structure showed that $72 \%$ of the cattle belonged to the category of cattle younger than 1 year, and $17 \%$ were between 1 and 2 years of age. On average, 75\% of the feed used for the animals was produced on the farm. Swedish beef producers are attracted by the funding provided to farmers to produce organically. Nearly $50 \%$ of all farm producers are converting to (at least partially) or producing organically. Approximately $60 \%$ of the farms included in the analysis were situated in the southern and central plains area (FADN Region 1), with a grazing season of at least 3 months (mostly in grazing region 2). Only $7 \%$ of the beef farms were in northern Sweden (FADN Region 3) (9\% in grazing region 3), where the grazing period is less than 3 months.

\section{Results and discussion Technical efficiency and input saving possibilities}

A summary of statistics on the technical efficiency (TE) measures obtained from the efficiency analysis (CRDF and GDDF) are presented in Table 3.

Table 3. Efficiency estimates, country and regional specifics.

\begin{tabular}{|c|c|c|c|c|c|c|}
\hline \multirow[b]{2}{*}{ Technical efficiency } & \multirow{2}{*}{ Number of observations } & \multicolumn{2}{|c|}{ Radial (CRDF) } & \multicolumn{2}{|c|}{ Directional (GDDF) } & \multirow{2}{*}{$\begin{array}{c}\text { Spearman's rank } \\
\text { correlation }\end{array}$} \\
\hline & & Mean & $\begin{array}{l}\text { Std } \\
\text { err }\end{array}$ & Mean & Std. err. & \\
\hline Country & 381 & .75 & .010 & .82 & .008 & .93 \\
\hline \multicolumn{7}{|l|}{ Regional specifics ${ }^{1}$} \\
\hline FADN Region 1 & 240 & .75 & .013 & .82 & .010 & .94 \\
\hline FADN Region 2 & 115 & .75 & .015 & .82 & .014 & .88 \\
\hline FARN Region 3 & 26 & .74 & .047 & .81 & .035 & .94 \\
\hline Grazing region 1 & 78 & .80 & .022 & .85 & .017 & .97 \\
\hline Grazing region 2 & 270 & .74 & .012 & .81 & .009 & .91 \\
\hline Grazing region 3 & 33 & .71 & .040 & .79 & .029 & .92 \\
\hline
\end{tabular}

Average estimated TE was $75 \%$ for the classical radial and $82 \%$ for the generalized distance function method, implying that farmers could decrease their costs by an average of $25 \%$ and $18 \%$, respectively. Although the average values of the TE estimates differed, the Spearman rank correlation showed positive, statistically significant correlation of both frontiers ( $r=93 \%)$. The differences in the value of the coefficients can be expected to originate from the flexibility in the assumptions of the generalized approach where farms are expected to adopt the technology (inputs combination) of the pairs that are found closest on the efficiency frontier. Prioritization of model selection is not straightforward and besides the empirical reasoning (Cheng and Zervopoulos 2012, Färe and Grosskopf 2000), it also needs to be associated with the sample characteristics, and the resource endowments. A homogeneous data sample would probably provide smaller differences between the TE estimated with the two models. Swedish beef production is characterized by its heterogeneity, both in production practices (e.g. cow-calf systems vs. intensive fattening) and in regional factor endowments. In this study, both models were applied for comparison.

The highest average efficiency, 80\% (for CRDF) and 85\% (for GDDF), was recorded for farms located in grazing region 1 (characterized by a longer grazing season and suitable agricultural conditions). The TE estimates for farms located in grazing region 2 (typically with large areas of non-connected pastures, forest and major city agglom- 
erations) and grazing region 3 (with a very short grazing period) were lower, by about $7-11 \%$ for CRDF and 5-7\% for the GDDF approach. The average TE values for the FADN regions 1, 2 and 3 were similar, confirming findings by Manevska-Tasevska et al. (2013) in an analysis of the TE of Swedish beef farms 1998-2008 from an output-orientated perspective. The finding of regional differences in the estimated TE is an indication that a proper regional division based on production characteristics is necessary when regional policy decisions are being made. Data on average TE estimated for beef production systems in Europe is scarce and not up-to-date. However, based on the existing literature, French beef farms have a TE of 65\% (in 2000) (Latruffe et al. 2009). The average estimated TE of beef farms in the UK is 82\% for England (1992-2002) (Hadley 2006) and 77\% for Scotland (1989-2004) (Barnes 2008). The TE of beef farms in Kansas, USA, is similar to this (78\%) (Featherstone et al. 1997). In essence, efficiency coefficients are relative estimates showing the efficiency heterogeneity of the selected data sample. Therefore, comparisons and country rankings based on the efficiency estimates obtained in different studies should always be made with caution. The frequency distribution of TE at country level and for the Swedish grazing regions is given in Table 4. These results show that at country level, an efficiency level higher than $80 \%$ was attained by about $50 \%$ of farms in our sample (42 and $52 \%$ for CRDF and GDDF, respectively).

Table 4. Frequency distribution of predicted efficiency: country and regional specifics.

\begin{tabular}{lccccc}
\hline $\begin{array}{l}\text { Technical efficiency } \\
\text { Classical radial directional efficiency } \\
\text { Country level }\end{array}$ & $0-0.19$ & $0.20-0.39$ & $0.40-0.59$ & $0.60-0.79$ & $0.80-1.0$ \\
Grazing region 1 & $0 \%$ & $4 \%$ & $22 \%$ & $32 \%$ & $42 \%$ \\
Grazing region 2 & $0 \%$ & $2 \%$ & $17 \%$ & $22 \%$ & $59 \%$ \\
Grazing region 3 & $0 \%$ & $2 \%$ & $24 \%$ & $37 \%$ & $37 \%$ \\
Generalised radial directional efficiency \\
Country level & $0 \%$ & $12 \%$ & $24 \%$ & $21 \%$ & $43 \%$ \\
Grazing region 1 & $0 \%$ & $0 \%$ & $8 \%$ & $40 \%$ & $52 \%$ \\
Grazing region 2 & $0 \%$ & $0 \%$ & $5 \%$ & $33 \%$ & $62 \%$ \\
Grazing region 3 & $0 \%$ & $0 \%$ & $8 \%$ & $43 \%$ & $49 \%$ \\
\hline
\end{tabular}

Full TE was attained by 80 farmers ( $21 \%$ of the total data sample). Farmers belonging to the region with the longest grazing period (grazing region 1) had the highest possibility (about 60\%) to reach efficiency higher than $80 \%$. Farmers located in regions with a shorter grazing period (grazing regions 2 and 3) were less successful. In these regions, 37\% (CDRF) and 55\% (GDDF) of the farms attained efficiency higher than $80 \%$, and $8 \%$ (CRDF) and 36\% (GDDF) attained efficiency between 20-59\%. Manevska-Tasevska et al. (2013) have shown that under an assumption of output orientation (where the ultimate goal is revenue maximization instead of cost minimization), around $30 \%$ of Swedish beef producers operate at TE lower than $80 \%$. Compared with the current study, Swedish farmers face greater challenges in using an appropriate input combination (since around $50 \%$ of the beef producers had TE lower than $80 \%$ ) rather than obtaining higher output value. However, it is worth mentioning that ManevskaTasevska et al. (2013) considered the income coming from subsidies as a farm output value and thus to a large extent equalized the potential agricultural differences between farms.

As mentioned previously, the average potential for cost reduction in Swedish beef production was estimated to be $25 \%$ (CRDF) and 18\% (GRDF). As can be seen from the results presented in Table 5, the input saving possibilities were highest for animal handling costs and energy costs. Animal handling costs can be decreased on average by $38 \%$ (CRDF) and $48 \%$ (GDDF), depending on the model selection. This is an indication that there are huge variations in animal handling costs between beef producers. The animal handling costs comprise a large number of livestock-specific costs (such as veterinary fees, medical costs, registration in herd books, maintenance of livestock equipment, short-term rent of buildings used to house animals or storage, marketing etc.). Thus the variation can be connected to a large extent to variations in the cost structure. Differences in animal handling costs may also be linked to different beef production systems (e.g. cow-calf systems vs. fatteners). The country-level average possibility for energy saving was about 35\% (CRDF) and 32\% (GDDF). Differences in the energy and animal handling costs among farms operating in the selected grazing regions were an expected outcome. 
Table 5. Input saving possibilities*, country and regional specifics, for the classical radial and generalised directional distance functions.

\begin{tabular}{|c|c|c|}
\hline Variables/inputs & Radial (CRDF) & Directional (GDDF) \\
\hline Labour use & .28 & .24 \\
\hline Labour use in grazing region 1 & .22 & .19 \\
\hline Labour use in grazing region 2 & .30 & .25 \\
\hline Labour use in grazing region 3 & .29 & .20 \\
\hline Total area utilised & .32 & .32 \\
\hline Total area utilised in grazing region 1 & .28 & .29 \\
\hline Total area utilised in grazing region 2 & .33 & .34 \\
\hline Total area utilised in grazing region 3 & .31 & .26 \\
\hline Feed costs & .29 & .24 \\
\hline Feed costs in grazing region 1 & .25 & .21 \\
\hline Feed costs in grazing region 2 & .30 & .25 \\
\hline Feed costs in grazing region 3 & .30 & .25 \\
\hline Animal handling costs & .38 & .48 \\
\hline Animal handling costs in grazing region 1 & .34 & .40 \\
\hline Animal handling costs in grazing region 2 & .39 & .50 \\
\hline Animal handling costs in grazing region 3 & .38 & .62 \\
\hline Energy costs & .35 & .32 \\
\hline Energy costs in grazing region 1 & .26 & .24 \\
\hline Energy costs in grazing region 2 & .38 & .35 \\
\hline Energy costs in grazing region 3 & .38 & .27 \\
\hline Livestock units & .29 & .30 \\
\hline Livestock units in grazing region 1 & .25 & .26 \\
\hline Livestock units in grazing region 2 & .30 & .31 \\
\hline Livestock units in grazing region 3 & .32 & .29 \\
\hline
\end{tabular}

*Note: Input saving possibilities = 1- (projected input use /original input use)

A longer grazing season is associated with better weather conditions and thus a longer outdoor stay, which decreases costs associated with keeping animals indoors and maintenance of buildings. To decrease the energy costs of Swedish beef producers, Nyman (2009) suggest outdoor wintering, but at the same time point out that the climate and soil conditions are not appropriate for this. Investment in energy-saving technology could be another alternative.

On average, labour, livestock units and feed were the most efficiently used, indicating relatively balanced production/managerial practices where these inputs are concerned. Data on labour use in EU member states place Sweden as the second most labour-efficient country, producing 42 finished cattle per labour unit, with Denmark taking first place (93 finished cattle/labour unit) (European Commission 2013). However, it is important to emphasize that feed costs make up the largest share of the variable costs on livestock farms (Manevska-Tasevska et al. 2013), implying that even a small contribution to the costs savings in this area may have a great impact in decreasing total farm variable costs. Clearly, as the average TE in grazing region 1 was highest, discrepancies in the input costs (all inputs in general) among the farmers operating in that region are lower. Scores estimated with the CRDF approach, and therefore the saving possibilities for input use, for farmers operating in grazing regions 2 and 3 were similar. However, scores obtained with the GDDF approach showed higher input saving possibilities for labour use and energy costs in grazing region 2 than in grazing region 3. For example, labour use on farms operating in grazing regions 2 and 3 could potentially decrease by $25 \%$ and $20 \%$, respectively. The potential decrease in the energy costs was $35 \%$ (grazing region 2 ) and $27 \%$ (grazing region 3 ). 


\section{Determinants of input-saving technology}

Findings on the determinants of input-saving technology for beef production systems in Sweden are shown in Table 6. The need to increase the number of animals on beef farms is one of the key issues discussed by Swedish practitioners and researchers (e.g. Kumm 2005, Kumm 2006, Nyman 2009, Salevid 2013). However, this study showed that larger farms apply less efficient input-saving technology, so H:FS1 was rejected. In two recent studies, Manevska-Tasevska et al. (2013) and Finneran and Crosson (2013) found respectively that Swedish and Irish beef production exhibit decreasing returns to scale, implying that farms are larger than the optimal scale. In both cases, structural changes rather than scale changes are suggested.

Table 6. Regression analysis: determinants of input-saving technology for Swedish beef production systems

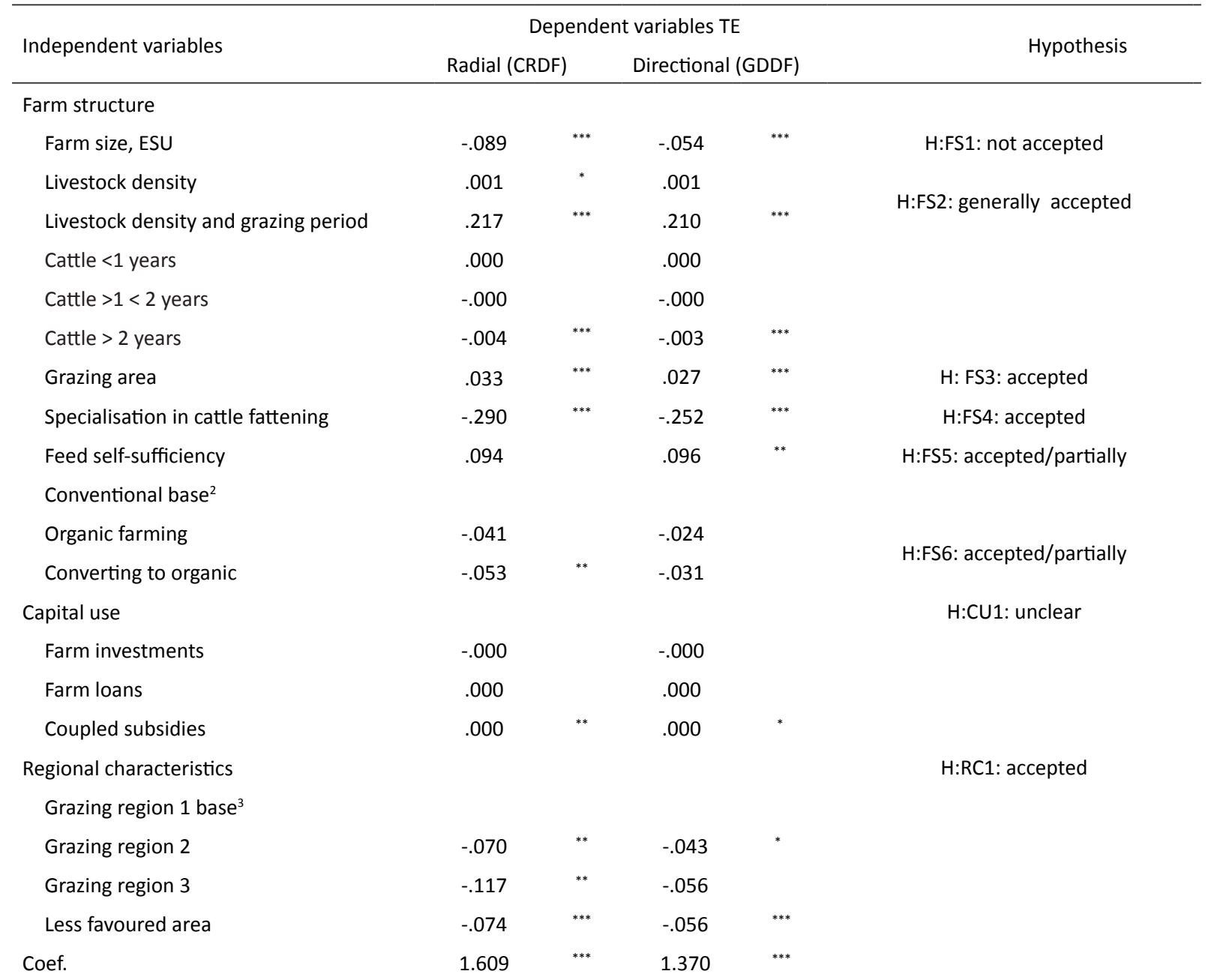

Note $1:{ }^{*}$ statistically significant at $10 \%,{ }^{* *}$ statistically significant at $5 \%,{ }^{* * *}$ statistically significant at $1 \%$.

${ }^{2}$ Note: the signs obtained for organic farming and converting to organic refer to the difference in TE potential compared with conventional farming.

${ }^{3}$ Note: the signs obtained for grazing regions 2 and 3 refer to the difference in TE potential compared with grazing region 1.

US beef producers (Featherstone et al. 1997) have also been advised to focus on using their capital, feed and labour more efficiently rather than adjusting herd size. In the present study, farm size was measured in economic terms (ESU), so the income effect (Becker 1965) reducing the farmers' effort to produce efficiently can also be an explanation. Furthermore, studies analysing the economics of beef production systems suggests that large-scale cattle fattening enterprises are efficient only when there is no shortage of feed resources (Huyen et al. 2010, Krasachat 2007, Sarma and Ahmed 2011). If the availability of feed resources are limited, small-scale cattle fattening enterprises are reported to be more profitable and flexible (Sarma and Ahmed 2011). Even in large-scale beef herd enterprises in the US, where herd size has been found to have a positive impact on production costs, it is claimed that this does not necessarily improve productivity per se (Ramsey et al. 2005). According to Nyman (2009), the increase in herd size in Sweden needs to be followed by providing larger, more connected pastures. However, such a measure would require complex political and managerial decisions on Swedish pasture management. 
In this study, farmers having larger pasture areas were found to be statistically more efficient, supporting H:FS3 and confirming that larger pasture areas and grazing mean low-cost feeding for the animals. Grazing is expected to contribute to feed self-sufficiency, decreasing the feed costs and the costs associated with maintaining the cattle facilities. In the present study the influence of feed self-efficiency was positive, but statistical significance was found only for the GDDF approach, so hypothesis H:FS5 was partially confirmed. A crucial issue in grazing management is the livestock density. Based on the results obtained here, the influence and the significance of livestock density increase with increasing length of grazing period (see the Livestock density \& grazing variable in Table 6). Greater concentration of animals per total area utilized (which is typical for intensive beef fattening systems) had inputs saving effects, confirming $\mathrm{H}: \mathrm{FS} 2$, and this effect became stronger as the grazing period increased. However, intensive beef fattening systems implies higher pressure of livestock farming on the environment, in terms of difficulties in preserving biodiversity. This study did not include: 1 ) the negative outputs (the environmental footprint of the beef production systems) or 2) measures of positive environmental impacts, so clear evidence of environmental damage and the optimal livestock density per unit area utilized cannot be provided. Such an analysis could be of great importance for future research.

Furthermore the analysis showed that farms with more animals older than 2 years were statistically less efficient. Intuitively, this means that farmers should try to sell their livestock at a younger age. Livestock density and herd structure are both highly associated with type of production system (cow-calf vs. intensive fattening), so generalizations based on the present findings are scarcely acceptable. As such characteristics are production related, more accurate results would be obtained if detailed data on the characteristics of the production systems were available.

Proper use of farm inputs was found to be negatively influenced by the degree of farm specialization, supporting hypothesis H:FS4. This confirms findings in previous studies, where the need for diversification of farm production is associated with the availability of feed and the risk of changes in feed prices (Featherstone et al. 1997, Langemeier et al. 1992, McBride and Mathews 2011). According to Rizov et al. (2012), the decision to diversify production and thus manage the input price risk and ensure a better outcome in an uncertain production environment needs to be carefully considered.

Furthermore, the results on efficiency without environmental support were statistically significant only for farms in the process of converting to organic production, so hypothesis $\mathrm{H}$ :FS6 was partially confirmed. One possible explanation for this finding, which seems to be idealistic, is that the market for organic beef meat is working properly and the price received for the production compensates for the losses generated by the technological restrictions. Farmers transferring to organic can have high costs associated with converting to organic technology practices but do not receive a premium for their production, which is still not organically certified. Another explanation for the lack of statistically significant results for organic production is the structure of the dataset, which contained very few organic farms (4\%). The economic success of organic beef production systems in Sweden (Kumm 2009, Salevid and Kumm 2011) and the Czech Republic (Hrabalova and Zander 2006) has previously been related to a high level of environmental payments. Swedish farms producing organically receive higher amount of the farm support, to compensate for costs generated in meeting environmental requirements (Manevska-Tasevska et al. 2013).

Capital use considered in terms of farm loans and farm investments was not found to have a statistically significant influence on the input saving possibilities. However, the results were not statistically significant, so we cannot confirm hypothesis H:CU1. The impact of capital use on the efficiency of Swedish beef farms thus remains unclear. Previously, Ramsey et al. (2005) and Finneran and Crosson (2013) found that investment on beef farms in US and Ireland, respectively, is unrelated to higher economic benefits. Manevska-Tasevska et al. (2013) claim that even the investment subsidy has not succeeded in improving the TE of Swedish beef farms. Previous studies on specific investments on cattle farms have mainly focused on e.g. breeding technology (Archer et al. 1999, Herd et al. 2003), investments in robotic milking systems (Bergman and Rabinowicz 2013) and managerial practices based on information systems (Nuthall 2004). A recent study on adaptation to robotic milking systems in Sweden showed improvements in animal welfare and the working conditions of farmers, but not in farm profitability (Bergman and Rabinowicz 2013). There is thus uncertainty concerning farm efficiency and milking robot technology. A positive and statistically significant influence was observed for income support subsidies. The latest report on beef production in EU member countries claims that since 2010 the gross margins are at their lowest level, being reasonable only when the coupled payments are taken into account (European Commission 2013). Coupled payments to beef producers are indeed provided as fundamental income support to keep farms in existence. The uncertainty regarding the effects of capital utilization on the efficiency of Swedish beef farms is an indication of the need for more detailed analysis of investments and asset value. 
Regional variables showing the duration of the grazing period gave clear signals that TE increased with a longer grazing period. Compared with farms operating in the region with a four-month grazing period (grazing region 1), farms with a three-month period (grazing region 2, characterized by non-connected pastures, forest and major city agglomerations) and a two-month grazing period (grazing region 3, typically with a short grazing period), attained $7 \%$ and $11 \%$ lower TE, respectively (CRDF approach). Note that grazing region 1 is the main crop production region in Sweden, so its farmers are less constrained on feed availability in general. Farms operating in LFA are also a category where lower efficiency is expected. We found a negative and statistically significant influence on the input saving possibilities, indicating the difficulties in saving on inputs in these areas. Even with support payments considered as part of total income, Swedish beef producers operating in LFA have been found to be insufficiently compensated (Manevska-Tasevska et al. 2013). A common finding is for LFA to have a negative impact on farm efficiency (e.g. Barnes 2008). Both findings confirm hypothesis H:RC1, i.e. the existence of region-specific TE.

\section{Conclusions and policy implications}

This study comprised three main parts. First, the relative possibilities for cost decreases and improvements in the use of inputs in a sample of Swedish farms specialising in beef production (2008-2011) were estimated using multi-output, multi-input distance function analysis. Second, a comparative analysis was made of the classical radial and generalized non-parametric approaches. Third, the influence of selected structural, capital and regional farm characteristics on input saving possibilities was examined.

The results showed that on average, farm costs could be decreased by $25 \%$ (classical radial approach) and $18 \%$ (generalized approach). The highest discrepancies were detected for animal handling costs and energy costs. Although different values of average TE were obtained, both models constructed frontiers where farm ranking values were positively and highly correlated (Spearman rank correlation approx. 93\%). In addition, similar results in terms of the size and significance of the parameter estimates were obtained with the two models. Input-saving technologies were found to be positively influenced by livestock density, pasture availability and the use of coupled income support. Larger farms, farms with greater specialisation in beef production, farms with a larger number of animals older than 2 years, farms converting to organic production, farms located in LFA and farms located in regions with a shorter grazing period were found be less efficient.

The efficiency analyses conducted of farms specialising in beef production improved our understanding of how beef production can be encouraged from a policy point of view to increase its productivity and therefore contribute to societal goals about rural employment, biodiversity and reduced environmental impacts. Rather than simply encouraging farm growth, policy measures are more likely to be successful if targeted towards the establishment of beef farms in favourable regions and towards taking the development of feed resources into consideration. As diversified farms were found to be more efficient, a policy encouraging farms to run more than one agricultural enterprise seems plausible. Furthermore, organic production is socially accepted as environmentally friendly, but farmers converting to organic find it difficult to be economically sustainable. Therefore, policy support designed to follow the steps of transition to organic production is credible.

The results provided here refer to the use of inputs and the factors influencing efficient use of inputs by a sample of Swedish beef producers on an aggregated level, but some critical issues uncovered are generally applicable. Further studies providing details of region- and production-specific (e.g. cow-calf vs. intensive fattening), positive and negative outputs, obtained using meta-frontier/cluster analysis) would be a useful complement.

\section{Acknowledgements}

The authors thank the two anonymous reviewers, Bengt Johnsson and the research group from the AgriFood economics center - Sweden, for their time, and all comments and suggestions on the earlier drafts of the manuscript.

\section{References}

Afonso, A. \& St. Aubyn, M. 2006. Cross-country efficiency of secondary education provision: A semi-parametric analysis with nondiscretionary inputs. Economic Modelling 23: 476-491.

Alene, A.D. \& Zeller, M. 2005. Technology adoption and farmer efficiency in multiple crops production in eastern Ethiopia: A comparison of parametric and non-parametric distance functions. Agricultural Economics Review 6: 5.

Alvarez, A., del Corral, J., Solís, D. \& Pérez, J.A. 2008. Does intensification improve the economic efficiency of dairy farms? Journal of Dairy Science 91: 3693-3698. 
Archer, J. \& Bergh, L. 2000. Duration of performance tests for growth rate, feed intake and feed efficiency in four biological types of beef cattle. Livestock Production Science 65: 47-55.

Archer, J., Richardson, E., Herd, R. \& Arthur, P. 1999. Potential for selection to improve efficiency of feed use in beef cattle: a review. Australian Journal of Agricultural Research 50: 147-162.

Asmild, M., Bogetoft, P. \& Hougaard, J.L. 2013. Rationalising inefficiency: a study of Canadian bank branches. Omega 41: 80-87.

Avery, A. \& Avery, D. 2007. The environmental safety and benefits of growth enhancing pharmaceutical technologies in beef production. Hudson Institute, Center for Global Food Issues, Washington, DC.

Avery, A. \& Avery, D. 2008. Beef production and greenhouse gas emissions. Environmental Health Perspectives 116: A374.

Barnes, A. 2008. Technical efficiency estimates of Scottish agriculture: A Note. Journal of Agricultural Economics 59: 370-376.

Barnes, A.P., Revoredo-Giha, C. \& Sauer, J. 2011. A metafrontier approach to measuring technical efficiencies across the UK dairy sector, Evidence-based agricultural and rural policy making: methodological and empirical challenges of policy evaluation, February 17-18, 2011, Ancona, Italy.

Becker, G.S. 1965. A theory of the allocation of time. The economic journal 75: 493-517.

Bergman, K. \& Rabinowicz, E. 2013. The adoptation of the automatic milking systems among swedish milk producers. Working paper, 2013:8. AgriFood Economic Centre, Department of Economics, Swedish University of Agricultural Sciences, Lund.

Bogetoft, P. \& Hougaard, J.L. 2003. Rational inefficiencies. Journal of Productivity Analysis 20: 243-271.

Bostad, E., Swensson, C. \& Pinzke, S. 2011. Labour input in specialist beef bull production in Sweden. Agricultural Engineering International: CIGR Journal 13.

Brady, M., Kellermann, K., Sahrbacher, C. \& Jelinek, L. 2009. Impacts of decoupled agricultural support on farm structure, biodiversity and landscape mosaic: Some EU results. Journal of Agricultural Economics 60: 563-585.

Chambers, R.G., Chung, Y. \& Färe, R. 1996. Benefit and distance functions. Journal of economic theory 70: 407-419.

Chambers, R.G., Chung, Y. \& Färe, R. 1998. Profit, directional distance functions, and Nerlovian efficiency. Journal of Optimization Theory and Applications 98: 351-364.

Cheng, G. \& Qian, Z. 2010. MaxDEA Linear Programming, Version 5.2 (computer) programme, http://maxdea.cn/ Accessed February 15, 2013.

Cheng, G. \& Zervopoulos, P. 2012. A generalized directional distance function in data envelopment analysis and its application to a cross-country measurement of health efficiency. No. 42068. University Library of Munich, Germany.

Coelli, T. \& Perelman, S. 1999. A comparison of parametric and non-parametric distance functions: With application to European railways. European Journal of Operational Research 117: 326-339.

Coelli, T.J., Rao, D.S.P., O’Donnell, C.J. \& Battese, G.E. 2005. An introduction to efficiency and productivity analysis. New York, USA:Springer Science+Business Media, LLC.

European Commission 2011. Impact assessment. CAP towards 2020. Direct payments. In: D.-G.f.A.a.R. (ed.) Development. European Commission, Brussels, 2011.

European Commission 2013. EU Beef farms report 2012, Directorate L. Economic analysis, perspectives and evaluations. L3 Microeconomic Analysis of EU agricultural holdings. European Commission, Unit L3 D (2013), Brussels, May, 2013.

Featherstone, A.M., Langemeier, M.R. \& Ismet, M. 1997. A Nonparametric analysis of efficiency for a sample of Kansas beef cow farms. Journal of Agricultural and Applied Economics 29: 175-184.

Finneran, E. \& Crosson, P., 2013. Effects of scale, intensity and farm structure on the income efficiency of Irish beef farms. International Journal of Agricultural Management 2: 226-237.

Färe, R. \& Grosskopf, S. 2000. Theory and application of directional distance functions. Journal of Productivity Analysis 13: 93-103.

Färe, R., Grosskopf, S. \& Margaritis, D. 2008. Efficiency and productivity: Malmquist and more. In: Fried, H.O., Lovell, C.A.K., Schmidt, S.S. (eds.). The measurement of productive efficiency and productivity change. New York: Oxford University Press.

Galanopoulos, K., Aggelopoulos, S., Kamenidou, I. \& Mattas, K. 2006. Assessing the effects of managerial and production practices on the efficiency of commercial pig farming. Agricultural Systems 88: 125-141.

Gaspar, P., Mesías, F.J., Escribano, M. \& Pulido, F. 2009. Assessing the technical efficiency of extensive livestock farming systems in Extremadura, Spain. Livestock Science 121: 7-14.

Greene, W.H. 2008. The econometric approach to efficiency analysis. In: Fried, H.O., Lovell, C.A.K., Schmidt, S.S. (eds.). The measurement of productive eficiency and productivity change. New York: Oxford University Press.

Hadley, D. 2006. Patterns in Technical Efficiency and Technical Change at the Farm-level in England and Wales, 1982-2002. Journal of Agricultural Economics 57: 81-100.

Hansson, H. 2007. Strategy factors as drivers and restraints on dairy farm performance: Evidence from Sweden. Agricultural Systems 94: 726-737.

Hansson, H. 2008. How can farmer managerial capacity contribute to improved farm performance? A study of dairy farms in Sweden Food Economics - Acta Agriculturae Scandinavica, Section C 5: 44-61.

Hansson, H. \& Ferguson, R. 2011. Factors influencing the strategic decision to further develop dairy production-A study of farmers in central Sweden. Livestock Science 135: 110-123.

Hansson, H. \& Ohlmer, B. 2008. The effect of operational managerial practices on economic, technical and allocative efficiency at Swedish dairy farms. Livestock Science 118: 34-43. 
Herd, R., Archer, J. \& Arthur, P. 2003. Reducing the cost of beef production through genetic improvement in residual feed intake: Opportunity and challenges to application. Journal of Animal Science 81: E9-E17.

Hrabalova, A. \& Zander, K. 2006. Organic beef farming in the Czech Republic: structure, development and economic performance. Zemedelska Ekonomika - Praha 52: 89.

Huyen, L.T.T., Herold, P. \& Valle Zárate, A. 2010. Farm types for beef production and their economic success in a mountainous province of northern Vietnam. Agricultural Systems 103: 137-145.

Jensen, J.D. \& Kristensen, I.T. 2013. Farm profitability and structural challenges - geographical patterns in the Danish agricultural economy. Geografisk Tidsskrift-Danish Journal of Geography 113: 39-52.

Krasachat, W. 2007. Economic efficiency of feedlot cattle farms in Thailand. King Mongkut's Institute of Technology Ladkrabang, Bangkok.

Kumbhakar, S.C. \& Lien, G. 2010. Impact of subsidies on farm productivity and efficiency. In: Ball, V.E., Fanfani, R., Gutierrez, L. (eds.). The economic impact of public support to agriculture. New York: Springer. p. 109-124.

Kumm, K.-I. 2005. Economically sustainable Swedish beef production by large-scale ranching and extensive pasture-mosaics, Integrating efficient grassland farming and biodiversity. Proceedings of the 13th International Occasional Symposium of the European Grassland Federation, Tartu, Estonia, 29-31 August 2005. Estonian Grassland Society, pp. 231-234.

Kumm, K., 2006. Vägar till lönsam nöt- och lammköttsproduktion (Translated from Swedish: Scenarios for profitable beef and lamb production). Rapport 11. The Department of Animal Environment and Health, Svedish University of Agricultural Sciences, Skara. $99 \mathrm{p}$.

Kumm, K.-I. 2009. Cost of roughage production to beef cattle. Department of Animal Environment and Health, Section of production systems, Skara, p. 10-20.

Kumm, K.-I. \& Larsson, M. 2007. Import av kött: export av miljöpåverkan. Raport 5671. Naturvårdsverket.

Langemeier, M., Schroeder, T. \& Mintert, J. 1992. Determinants of cattle finishing profitability. Southern Journal of Agricultural Economics 24: 41-41.

Larsén, K. 2010. Effects of machinery-sharing arrangements on farm efficiency: Evidence from Sweden. Agricultural Economics 41: 497-506.

Latruffe, L., Balcombe, K., Davidova, S. \& Zawalinska, K. 2004. Determinants of technical efficiency of crop and livestock farms in Poland. Applied Economics 36: 1255-1263.

Latruffe, L., Davidova, S. \& Balcombe, K. 2008. Application of a double bootstrap to investigation of determinants of technical efficiency of farms in Central Europe. Journal of Productivity Analysis 29: 183-191.

Latruffe, L., Guyomard, H. \& Mouël, C.L. 2009. The role of public subsidies on farms' managerial efficiency: An application of a five-stage approach to France. Working Paper INRA UMR SMART - LERECO N09-05.

Manevska-Tasevska, G. 2013. Product assortment and the efficiency of farms. In: Giraud-Héraud, E., Pichery, M.C. (eds.). Wine Econometrics. Quantitative Studies and Empirical Applications Palgrave Macmillan p. 250-265.

Manevska-Tasevska, G. \& Hansson, H. 2011. Does managerial behavior determine farm technical efficiency? A case of grape production in an economy in transition. Managerial and Decision Economics 32: 399-412.

Manevska-Tasevska, G., Rabinowicz, E. \& Surry, R.Y. 2013. Policy impact on farm level efficiency in Sweden: 1998-2008, Working paper 2013:06. Agrifood Economics Centre, Department of Economics, Swedish University of Agricultural Science, Lund.

Martin, G., Martin-Clouaire, R., Rellier, J.-P. \& Duru, M. 2011. A simulation framework for the design of grassland-based beefcattle farms. Environmental Modelling \& Software 26: 371-385.

McBride, W. \& Mathews, K. 2011. The diverse structure and organization of US beef cow-calf farms. USDA-ERS Economic Information Bulletin.

McCloud, N. \& Kumbhakar, S.C. 2008. Do subsidies drive productivity? A cross-country analysis of Nordic dairy farms. In: Chib, S., Griffiths, W., Koop, G., Terrell, D. (eds.). Bayesian econometrics: Advances in econometrics. Emerald Group Publishing Limited. p. $245-274$.

Nordin, M. \& Manevska-Tasevska, G. 2013. Farm-level employment and direct payment support for grassland use: A case of Sweden. Working paper, 2013:5. AgriFood Economic Centre, Lund University.

Nuthall, P.L. 2004. Case studies of the interactions between farm profitability and the use of a farm computer. Computers and Electronics in Agriculture 42: 19-30.

Nyman, S. 2009. Can Swedish beef production become profitable by learning from Canadian beef production? Thesis work, Report 290 Skara: Department of Animal Environment and Health Section of Production Systems, Swedish University of Agricultural Sciences.

O'Neill, S., Leavy, A. \& Matthews, A. 2002. Measuring productivity change and efficiency on Irish farms. Farm \& Food 12: 4-5.

Phillips, C. \& Sorensen, J.T. 1993. Sustainability in cattle production systems. Journal of Agricultural and Environmental Ethics 6: 61-73.

Ramsey, R., Doye, D., Ward, C., McGrann, J., Falconer, L. \& Bevers, S. 2005. Factors affecting beef cow-herd costs, production, and profits. Journal of Agricultural and Applied Economics 37: 91-99.

Rizov, M., Pokrivcak, J. \& Ciaian, P. 2012. CAP subsidies and productivity of the EU farms International Association of Agricultural Economists (IAAE) Triennial Conference, August 18-24, 2012, Foz do Iguacu, Brazil.

Salevid, P. 2013. Searching for economically sustainable Swedish suckle cow based beef production systems after decoupling of EU-income support, Department of Animal Environment and Health. Swedish University of Agricultural Sciencies, Skara. p. 64. 
Salevid, P. \& Kumm, K.-I. 2011. Searching for economically sustainable Swedish beef production systems based on suckler cows after decoupling EU income support. Outlook on Agriculture 40: 131-138.

Salevid, P. \& Kumm, K.-I. 2012. Profitability of organic and conventional cow-calf operations under Swedish conditions. Organic Agriculture: 1-13.

Sarma, P. \& Ahmed, J. 2011. An economic study of small scale cattle fattening enterprise of Rajbari district. Journal of the Bangladesh Agricultural University 9: 141-146.

SCB 2013. Official statistics of Sweden. Agriculture's statistical database. Online data base. Accessed, May 15, 2013

Shephard, R.W. 1953. Cost and production functions. DTIC Document.

Simar, L. \& Wilson, P.W. 2007. Estimation and inference in two-stage, semi-parametric models of production processes. Journal of Econometrics 136: 31-64

Sipiläinen, T., Kuosmanen, T. \& Kumbhakar, S.C. 2008. Measuring productivity differentials - An application to milk production in Nordic countries. In: Economists, E.A.o.A. (ed.), International Congress, August 26-29, 2008, Ghent, Belgium.

Swedish Board of Agriculture 2013. When your cattle are out on pasture: How animals for meat production must be kept on pasture. Accessed Juni, 262013.

Tobin, J. 1958. Estimation of relationships for limited dependent variables. Econometrica: Journal of the Econometric Society: 24-36.

Wang, X., Hockmann, H. \& Bai, J. 2012. Technical efficiency and producers' individual technology: Accounting for within and between regional farm heterogeneity. Canadian Journal of Agricultural Economics/Revue canadienne d'agroeconomie 60: 561-756. 